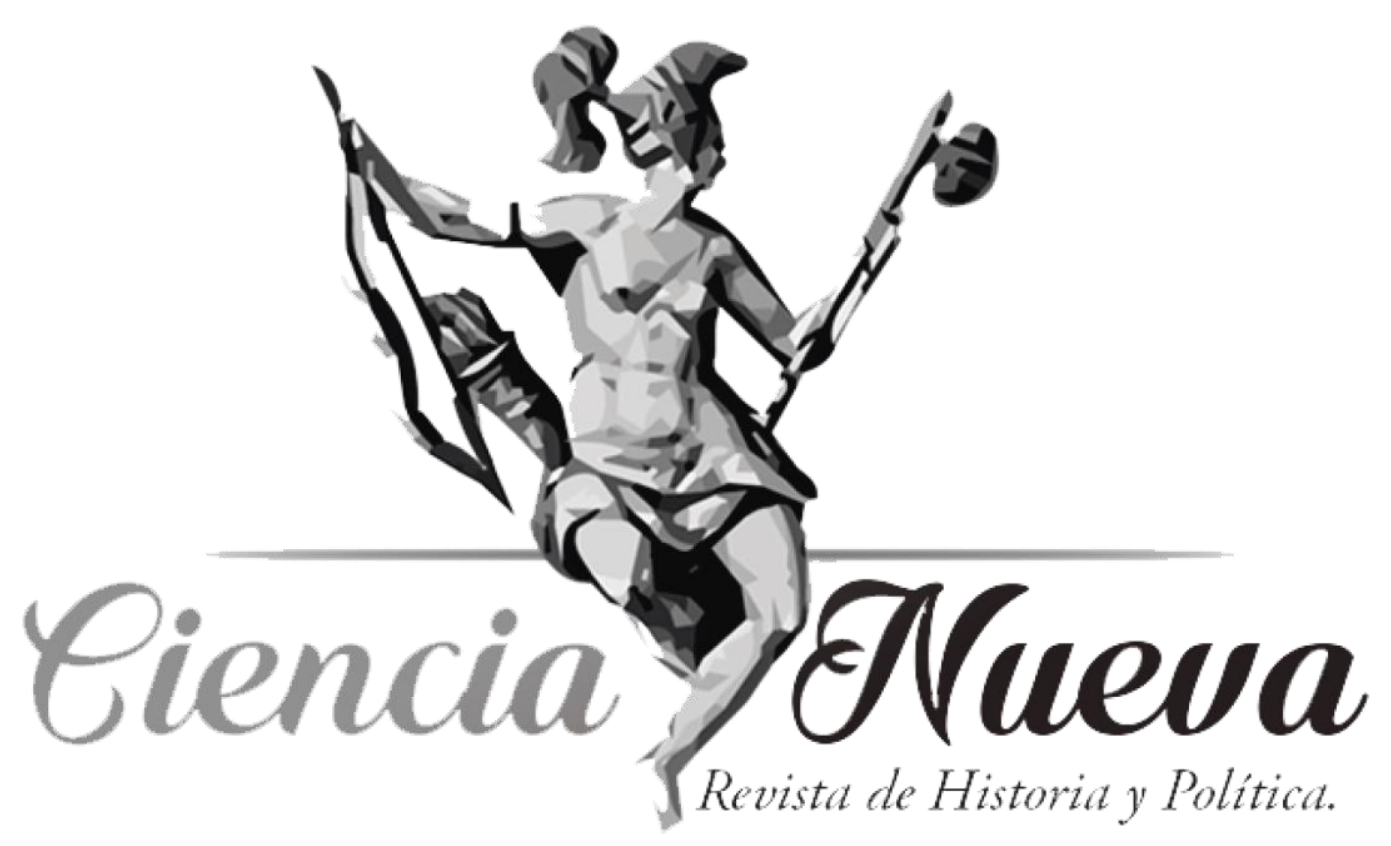

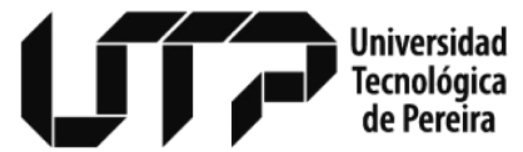

Maestría en Historia

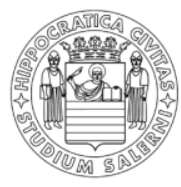

UNIVERSITÀ DEGLI STUDI DI SALERNO

Maestría en Ciencia Política

RESEÑAS

LARRY V. LARRICHIO. LA CONSTRUCCIÓN MULTICULTURAL DE UNA ECONOMÍA COLONIAL: CAMBIO DEMOGRÁFICO Y ORGANIZACIÓN DEL TRABAJO EN EL VALLE MEDIO DEL CAUCA SIGLO XVIII. PEREIRA: EDITORIAL UNIVERSIDAD TECNOLÓGICA DE PEREIRA, 2018

LARRY V. LARRICHIO. DEMOGRAPHIC CHANGE AND THE ORGANIZATION OF LABOR IN THE MIDDLE CAUCA VALLEY OF COLOMBIA DURING THE $18^{T H}$ CENTURY. PEREIRA: EDITORIAL UNIVERSIDAD TECNOLÓGICA DE PEREIRA, 2018

DOI: https://doi.org/10.22517/25392662.20791

Edwin Mauricio López García

pp. $217-220$

Vol. 3 Núm. 1 | Enero-Junio de 2019 Pereira, Colombia 


\title{
LARRY V. LARRICHIO. LA CONSTRUCCIÓN MULTICULTURAL DE UNA ECONOMÍA COLONIAL: CAMBIO DEMOGRÁFICO Y ORGANIZACIÓN DEL TRABAJO EN EL VALLE MEDIO DEL CAUCA SIGLO XVIII. PEREIRA: EDITORIAL UNIVERSIDAD TECNOLÓGICA DE PEREIRA, 2018*
}

\author{
LARRY V. LARRICHIO. DEMOGRAPHIC CHANGE AND THE ORGANIZATION \\ OF LABOR IN THE MIDDLE CAUCA VALLEY OF COLOMBIA DURING THE \\ 18TH CENTURY. PEREIRA: EDITORIAL UNIVERSIDAD TECNOLÓGICA DE \\ PEREIRA, 2018
}

\author{
Edwin Mauricio López García** \\ elopgar86@utp.edu.co
}

ORCID: http://orcid.org/0000-0002-1280-9072

$\begin{array}{cl}\text { Recibido: } & 28 \text { de enero de } 2019 . \\ \text { Revisado: } & 02 \text { de mayo de } 2019 . \\ \text { Aceptado: } & 20 \text { de mayo de } 2019 . \\ \text { Publicado: } & 30 \text { de junio de } 2019 .\end{array}$

$\mathrm{E}$ 1 trabajo del profesor Larry Larrichio se constituye en una ventana que permite explorar un periodo histórico de la colonia, que a nivel regional no ha sido revisado a mayor profundidad. Pues los historiadores profesionales o académicos del centro occidente colombiano han tenido en la mira otras etapas históricas, mayoritariamente se han decantado por estudiar el origen del proceso de subyugación y dominio de los españoles sobre los grupos indígenas conocido como "la conquista", y el proceso de poblamiento y fundación de localidades ocurrido desde inicios del siglo XIX hasta principios del XX, el cual se ha denominado "colonización antioqueña". De esta forma, esta obra entrelaza y sirve como puente entre la conquista española y la colonización antioqueña, puntos focales que dentro de la historiografía regional han sido los dos procesos sociales del pasado sobre los cuales se ha construido una visión histórica regional, pero que se ha desentendido por obtener una comprensión diacrónica del pasado.

En este sentido, la presente obra revela matices de la sociedad colonial antes desconocidos, en parte porque las obras históricas regionales se han enfocado en describir el proceso de conquista del mariscal Jorge Robledo y las fundaciones de las ciudades de Cartago, Anserma y Arma, sin adentrarse en estudiar esta misma zona geográfica en siglos posteriores, a excepción de los trabajos de los profesores Víctor Zuluaga Gómez y Albeiro Valencia Llano.

Por ello, la relevancia de este trabajo recae, primero, en el acotamiento de dicho salto historiográfico dando luz a un periodo oscuro en el devenir histórico regional y, segundo, en

\footnotetext{
* Esta reseña respeta las directrices y normas dispuestas en la Declaración de Ética de Publicación de Ciencia Nueva, Revista de Historia y Política. Esta declaración puede consultarse en la página web de la revista: revistas.utp.edu.co/index.php/historia.

** Licenciado en Etnoeducación y Desarrollo Comunitario de la Universidad Tecnológica de Pereira. Integrante del Grupo de Investigación Políticas, Sociabilidades y Representaciones Histórico-Educativas (PSORHE).
} 
la complejidad metodológica y teórica del trabajo que combina la interdisciplinariedad de la consulta de fuentes documentales en el Archivo Histórico de Cartago y el Archivo General de la Nación con el trabajo de campo en Pereira, Cartago y trayectos aún subsistentes del antiguo camino real del Quindío; conjuga también el estudio geográfico, ecológico y climático de la región para lograr una interpretación con múltiples variables al explicar la organización del trabajo en el Valle Medio del Cauca en el siglo XVIII. Además, resalta dentro de la consulta documental, el análisis pormenorizado de la terminología exacta contenida en las fuentes con el lenguaje propio de dicha época, que describe a los habitantes de la región para el periodo estudiado, haciendo un seguimiento exhaustivo tanto de los calificativos raciales y étnicos como de las categorías laborales de las personas que componen dicha sociedad colonial. De esta forma, el autor puede dar cuenta de la composición multicultural regional como consecuencia del proceso de mestizaje, lo cual permite superar el arquetipo del mundo colonial organizado de acuerdo con estructuras rígidas y jerárquicas, resaltando matices que revelan el cambio y la ruptura de dicho orden colonial.

El libro se encuentra dividido en cinco capítulos, en el primero se hace una introducción al trabajo en la América colonial española y el Valle Medio del Cauca en la Nueva Granada. El segundo, realiza un recuento de los vestigios y documentos arqueológicos presentando una perspectiva histórica de la región. El tercero hace énfasis en las estrategias usadas por las élites locales para la provisión de mano de obra calificada y no calificada, así como la bifurcación de la economía colonial hacia la minería y la agricultura, sustentadas también en el desarrollo de actividades comerciales. El cuarto capítulo se concentra en el estudio del resguardo de Pindaná y su integración en dicha economía. Por último, se evalúa el papel del trabajo de los esclavos en las haciendas del Valle Medio del Cauca.

El desarrollo histórico colonial descrito por el autor está enmarcado en una periodización que se divide en tres momentos. El primero ocurre entre 1530 y 1580, se caracteriza como un periodo de conquista en el que jugaron un papel importante la extracción de metales preciosos y la reducción de los grupos indígenas, los cuales fueron agrupados en encomiendas. Luego, en el segundo periodo colonial entre 1585 y el siglo XVII, la región vivió un aislamiento geográfico, político y económico a causa de una precaria economía de subsistencia, los caminos malos, la disminución de la población nativa y el declive de las actividades mineras. Situación que contrasta con la última fase que tuvo lugar entre 1690 y finales del siglo XVIII, estudiada a profundidad por el autor en la obra y señalada como una etapa de prosperidad económica gracias a la interrelación de una economía minera, agrícola y mercantil, que desarrollaba labores de minería en el Chocó, el cultivo de caña de azúcar en las haciendas y la prestación de servicios de transporte de mercancías y viajantes que conectaba al Valle Medio del Cauca al resto de regiones del virreinato.

Larrichio sustenta su planteamiento argumentando que las élites locales de la ciudad de Cartago, como zona periférica del Imperio Español en el siglo XVIII, desarrollaron una serie ecléctica de estrategias para cubrir la necesidad de mano de obra calificada y no calificada, similar a las regiones centrales de México y Perú, aunque en menor medida. De esta forma, los criollos y peninsulares llegados en dicho siglo a la zona del Valle Medio del Cauca, que el autor delimita territorialmente entre las ciudades de Cali y Cartago, requirieron de mano de obra para adelantar las actividades de minería y agricultura en dicha región. Ante el declive de la población indígena debido al sometimiento y los trabajos forzados, la huida de los mismos a tierras altas desconocidas, su adaptación a los centros urbanos y el proceso de mestizaje, los colonos españoles optaron por la introducción de una gran cantidad de esclavos desde Cartagena de Indias y la concertación de trabajadores asalariados para laborar 
en las haciendas y en las minas. Así, su tesis principal demuestra que la construcción multicultural de la economía colonial del Valle Medio del Cauca se compone por múltiples variables que se entrecruzan tales como la demografía local, la disponibilidad de los recursos locales, la solidaridad de la élite, las retribuciones del mercado y la cultura indígena.

Las variables descritas anteriormente tenían un punto económico territorial que las concentraba y sobre el cual al mismo tiempo giraban. En consideración de Larrichio, este punto era "la hacienda", como centro social y económico que ordenaba la estructura organizativa del trabajo en la sociedad colonial cartagüeña del siglo XVIII. La hacienda congregaba a su alrededor toda la fuerza de trabajo con su diversidad étnica, a través del predominio de un complejo sistema de aparcería y diversificación de los acuerdos en la tenencia de la tierra que integraba las actividades agrícolas, mineras y mercantiles. El sistema de trabajo contaba con profesiones $\mathrm{u}$ oficios, tales como terratenientes, hacendados, estancieros, peones, concertados, mitayos, labradores, jornaleros, agregados, mayordomos, arrendatarios y terrajeros en el renglón agrícola; mineros y mazamorreros en la extracción de metales y sal; carpinteros, alarifes y albañiles en el sector artesanal; comerciantes, tratantes, arrieros, chasquis, cargueros y pulperos en el sector de transporte mercantil. Así, deja en claro cómo se interrelacionaban el potencial agrícola del Valle Medio del Cauca con la minería en el Chocó y las actividades de intercambio y transporte de bienes y personas hacia Antioquia, Santa Fe, Popayán, Cartagena y Quito.

Al mismo tiempo, la hacienda se convertía en un poderoso instrumento de hispanización, que, en medio de esa diversidad étnica, llevó a cabo procesos de aculturación mezclando diversos elementos culturales étnicos y de asimilación e incorporando los grupos étnicos a la cultura hispana. Todo esto da cuenta de la dinamización de una jerarquía social colonial en la que las identidades étnicas se desplazaban horizontalmente en cada segmento de la jerarquía racial o se salían de la misma con el proceso de mestizaje, el cual produjo el estrato social más amplio de la población en dicho siglo. No solo existieron las denominaciones de blancos, indios y negros, pues en los documentos el autor encontró los calificativos étnicos de españoles, blancos, vecinos, negros, mulatos, montañeses, indios, ladinos, forasteros, pardos, mestizos, etc. Sumado a esto, el resguardo de Pindaná en inmediaciones de la ciudad de Cartago, les permitió a los indígenas que lo integraban desarrollar distintas actividades laborales, articulándolos al circuito económico regional mediante el establecimiento de seis fondas a lo largo del Camino del Quindío, la provisión de forraje para las bestias de los arrieros y el traslado de bienes y mercancías en el río La Vieja con canoas propias dispuestas para tal servicio. Sin embargo, a pesar de la prosperidad de dicho resguardo, se debe señalar que era el único existente en la región, según Larrichio, debido a que la condición de indio, que estaba atada a una filiación territorial de pertenencia al resguardo, se fue diluyendo en tanto muchos de los nativos prefirieron ser trabajadores libres y estar sin la obligación de pagar los tributos forzosos que les eran exigidos. Por su parte, algunos de los esclavos, en especial aquellos que se clasificaron como mano de obra calificada, pudieron lograr su manumisión por medio de actividades económicas dentro de las haciendas y las minas. Ahora bien, el tratamiento dado en la obra a los esclavos africanos, si bien destaca el papel de algunos de ellos en la administración de las haciendas y los trapiches como mano de obra especializada, además de la posibilidad de algunos de ellos para comprar su manumisión, se queda corto a la hora de describir las relaciones de dominación y explotación de dicho grupo étnico, por lo que podría tener una visión más amplia. Razón por la cual, se resalta esta temática como una posible línea de investigación a futuro para contrastar las estructuras de dominio coloniales sobre los grupos africanos con 
las prácticas individuales o de conjunto de los esclavos para resistirse al orden social del siglo XVIII en el Valle Medio del Cauca.

Como conclusión, se reafirma la importancia de la publicación de esta obra dentro de la historia regional, por la renovación de la periodización historiográfica que se ha enfocado en la conquista y en la colonización antioqueña como los dos grandes referentes que constituyen la visión histórica del centro occidente colombiano, ya que permite superar la concepción de la historia como una disciplina que se enfoca en el proceso originario de la sociedad humana. Este estudio aporta una perspectiva diacrónica en el desarrollo histórico de la región, que en su análisis metodológico interdisciplinario de la economía colonial del Valle Medio del Cauca en el siglo XVIII integra diversas variables teóricas para analizar el pasado, tales como la disponibilidad de recursos, la población local, la solidaridad de élites y la cultura indígena. Lo que permitió al autor demostrar la integración de actividades agrícolas, mineras y mercantiles que conformaron un periodo de prosperidad económica regional, destacando la dinámica del orden social colonial por medio de las diversas identidades étnicas y la multiplicidad de profesiones u oficios. 